\title{
The Enhancement of the Urban Environment: Sustainable Mobility in Reggio Calabria
}

\author{
Antonio Taccone $e^{1, a}$ \\ ${ }^{1}$ Mediterranean University of Reggio Calabria, Department of Heritage, Architecture, Urban \\ planning, Salita Melissari, Feo di Vito, 89124 Reggio Calabria, Italy \\ ªtaccone@unirc.it
}

Keywords: Strategic planning, Accessibility, Urban Heritage, Soft Mobility.

\begin{abstract}
The proposal of a sustainable mobility project for the use of assets requires evaluations regarding the balances that regulate the territory and its functions that necessarily involve the introduction of the concept of quality. The efficiency of public transport and collective services, the well-kept historical center, the suburbs integrated and connected with the entire city, a strong morphological and cultural identity of the settlement, are, on the whole, the results that a careful project of the territory should be able to achieve. This contribution intends to deal with the issue of public mobility and accessibility in a view of territorial development linked to the use of the urban area asset of Reggio Calabria.
\end{abstract}

\section{Introduction}

The proposed theme concerns the possibility of integrating a new system of mobility to the enhancement of the urban asset of Reggio Calabria. This necessity comes from an implicit need, which is to enhance and to promote a cultural and social use for the resources present in the territory and flows from new instances of a quality tourism that in Reggio Calabria, as well as in many other southern cities, require a careful search of new cultural desires with new destinations, which led to the discovery of products more rich of meaning and content, of authenticity, of identity. To promote a strategy that seeks the tools to activate the process of valorization of the urban asset of Reggio's territory seems like a winning project as the promotion of culture is a key factor for economic growth of the territory, both for its socio-economic characteristics that historically create a low capital intensity and a high component of intellectual activity, both for its rich symbolic and regional identity that characterize its social aspects.

\section{An ongoing project. The recent planning in Reggio Calabria}

The ambit in which Reggio stands, represent the terminal head of the Italian peninsula as well as the most studied territorial area in recent decades for the actual and potential relations with the Sicilian side. This condition has strongly influenced the urban area, populated by circa 180,000 inhabitants, which has a high concentration of functions with the presence of the University, the Conservatory, the Academy of Fine Arts and the University for Foreigners, the hospital poles, the Region and Province office, the airport, the port, the sports facilities and numerous administrative, production and sales activities of regional breath.

The data shown on the report of Euromobility 2012 [1] on the main 50 Italian cities, which analyzes in detail the state of the main indicators of urban mobility, describes the city of the Strait as the most unaffordable city sample (48 out of 50). Reggio, with its population density of 790.2 inhabitants $/ \mathrm{km}^{2}$ has an index of motorization in line with the Italian average $(60.77 \times \mathrm{Veh} / 100 \mathrm{Ab})$ with a vehicular density of approximately $500 \mathrm{Veh} / \mathrm{sq} \mathrm{km}$. The only quality that emerges from this table is an index of accident lower than the national average, while the death rate is higher. With regard to the limited traffic zone ( $1 \mathrm{sqm} /$ inhab. Pedestrian areas), paid parking (22 stalls stops for 1,000 cars circulating), interchange parks and cycle paths always maintain itself in the bottom places of the rankings. Only recently a small service of bike sharing has started the construction of a bike path already heavily discussed, while car sharing is yet all to experiment. In reality, the sector planning has created, over 
time, a multitude of projects and conditions to create a turnaround. Since the creation in 1995 of the new waterfront Falcomatà, it started however to move a slow but steady process of reorganization, aimed to improve the image, but also and above all the usability and accessibility to public places of the city.

Reggio can be defined as an ongoing project on mobility issues because in recent years there have been many interventions but especially designs that involved, directly or indirectly, aspects of movement, traffic and navigation mode. Another important aspect is the fact that Reggio has been using for a while "innovative" figures in the field of mobility: Mobility Business and Area Manager [2]. The first figure has functions of collecting information for the preparation of Travel Plans, preparation, monitoring and updating the home work Plans Moving [3], identification of projects to be proposed for the mobility of City employees. The second deals with the census of companies and organizations involved in mobility management, the connection actions with other services, local authorities and companies with expertise in mobility, coordination, monitoring and guide of the activities of the Corporate Mobility Manager, identification and coordination of projects related to the corporate mobility and movement of a systematic nature. The specific sector planning has focused on the development of different scenarios, one of the first is the Urban Traffic Plan (PGTU), prepared by SIPET and that regards, in respect of the Ministerial directives 24/06/1995, the measurements of the traffic flow, accidents analysis, public transportation, analysis, noise and air pollution. It has also worked to realize simulation models, of a computerized street land register and a road regulation and the modeling of alternative scenarios.

The second is the strategic plan for 2007-2013, prepared by the method of strategic planning, and is articulated into four actions, which in turn are articulated into fourteen specific objectives and a numerous operational objectives: Reggio node of relationships in the Mediterranean; Reggio competitive and attractive city; Reggio city to live, and Reggio united city. The specific objectives converge on employment growth, pursuing the goal of the Lisbon Strategy, and on the projection of a community that seeks its own space and its own recognition in the Mediterranean and international scenery.

The Agreement Program, construction of a new public transport system integrated area of Reggio Calabria and the Strategic Plan for sustainable mobility represent a turning point not only cultural but also realization. In fact, the agreement, which provided the creation of a new integrated system of metropolitan public transport, with the modernization of the existing rail system (from Bocale coming up to Villa S. Giovanni), has allowed the creation of the people mover system of Via Giudecca - tract between the Corso Vittorio Emanuele III and Via dei Filippini - and a system of elevation between Via dei Filippini and Via Possidonea. This system, in the Strategic Plan for sustainable mobility, is replicated with a project that involves, between Via Roma and the Riuniti Hospital, another treadmill, so to easily reach from the Hospitals the Lido station with a pedestrian path on level ground and secure. The Plan was originally planned (2009) form the signing of a Understanding Memorandum by, the President of the Regional Council, the mayors of the three municipalities of Cosenza, Catanzaro and Reggio and the Presidents of the Province for the use of funds allocated to the upgrading of their systems of transportation useful to reorganize urban mobility and accessibility of neighboring municipalities and encourage the development of a highly integrated metropolitan area.

For Reggio Calabria, the provided actions concerned: the strengthening of the coastal railways service, the connection of the central urban tissue with the main poles of attraction, located along the axis perpendicular to the coast (Hospitals, University Campus, Head Office, New Court, etc..) Enhancement of maritime links with the bank of Messina and the creation of a platform for the control of public transport and private traffic. The plan envisioned a system that would produce significant regional effects from Villa S. Giovanni to Melito Porto Salvo.

Of great importance is also the Urban Mobility Plan (PUM). The Town Council, dated 25.05.2010 with Directive Determination no. 1257 was awarded to the I.T. Transportation Engineering S.r.l. Company the assignment for the preparation of the Urban Mobility Plan. "The PUM represent a planning document of mobility aimed to the development and enhancement of "Reggio Calabria 
Mediterranean city" projected, in the area of the Strait as a whole economic, cultural and social system, and as a node of excellence of the regional, national and European infrastructure system [4].

The Urban Mobility Plan integrates the Strategic Plan of the city of Reggio Calabria and defines a set of priority actions in the field of mobility and its implications.

The reference scenarios of the drafting plan include existing infrastructure, those with work in progress, those planned with full financial coverage, the organizational and management actions for the optimization of the transportation system and for each reference scenario, with appropriate forecasting and simulation models, will be analyzed the criticality of the transportation system. The project scenarios will be obtained by adding to the reference scenarios the new infrastructural and technological interventions as well as the organizational and management ones for the optimization of the transportation system that will provide the PMU.

So, with this tool, the Administration also intends to follow up the projects previously expressed by the plans drawn up with the construction of multi-storey car parks, three new treadmills, new railway stations, two tram lines as well as other environmentally friendly design interventions PUM. The project will be based on the enhancement of pedestrians and, therefore, a fast and efficient transportation system made up of public means, for a city that can increasingly be on a human scale, as well as sustainable and livable.

The interventions to be completed are, in addition to the treadmill in via Giudecca, which is currently active from the Lungomare to Via Filippini, the creation of three other Treadmill (Stazione Lido up to the United Hospitals, University Town and connecting the areas of Engineering, Architecture and Agriculture Faculty), a train station nearby Via Giudecca, at the height of the treadmill, multi-storey car parks exchange (Museum of Sales, twain via Possidonea two at the Riuniti Hospital, one in Piazza Garibaldi and another one at the pinewood Zerbi, one in the area of Ce.Dir., and the new courthouse and another at the end of Viale della Libertà), a series of interventions to improve the traffic flow related to the railway line (all level crossings in urban area will disappear, allowing a better traffic flow and a better use of the coast and sea in the south area of the city), an important intervention linked to the project of city waterfront (to put underground the Central station) and two systems of sustainable mobility and environmentally friendly in a reserved and protected venue (the first between Viale della Libertà and the University Town, the second along the sea-mounts axis of the straps along the Calopinace, from Piazza Garibaldi to the Ce.Dir.).

The Urban Mobility Plan of Reggio Calabria provides the development in phases. The first phase has already been completed with a study of the current state and future demand, in the second phase it will be evaluated the "Zero Scenario" and the possible criticality through the interplay between demand and offer for all ways of transport. It will be elaborated, in the later stages, some project scenarios in terms of transportation, environmental, and territorial.

The Waterfront and the south urban Linear Park. One of the projects that more than others gave international exposure to the city was, without doubt, the project of the new configuration of Reggio Calabria Waterfront included in the stretch from the river Calolopinace to the Candeloro district. Among the many implications from the standpoint of urban mobility, the planned arrangement of the port area, which is still seen as a "other" space not in harmony with the city it would instead become whole with the urban organization of the waterfront. The project, in its organicity, provides numerous interventions all autonomous in a planning and financial sense. A first project, subject of an international contest of ideas launched by the Public Administration and awarded to the architect Zaha Hadid (financed with funds from the Reggio Decree) provides for the redevelopment and re-conversion of the coastal front for touristic activities, directional, tertiary, handcraft, commercial, with two symbol buildings: the Museum of the Mediterranean and the multifunctional Centre. Inside the museum are provided galleries, offices, archives and library, restoration workshops, an aquarium, dining centers and a communication area. The multifunctional center planned as a station for the fast connection shuttles via sea, will allow to get urban continuity with the city, through a pedestrian underpass that will connect the railway station with the town park. Are provided, also, an auditorium and a large covered square. 
Another project which the Administration has adopted and made in part is the South urban linear Park [5] that should be seen as the natural extension of the Waterfront affecting the area between the mouths of the rivers Calopinace and S. Agata. The purpose of the project is to redefine the relationship city - sea, making the area fully accessible and connect it longitudinally with the city; to provide the place with accommodation facilities that would determinate the improvement of the quality of life.

The whole system is developed on a main carriage able system that has its origin and destination in four targets: the river Calopinace, the structure of the Circolo Pescatori intended to accommodate social activities and leisure facilities as well as for boats towage and mooring, The Officine Omeca and the river Sant'Agata. In one of the target, in the vicinity of the Officine Omeca, it opens a square where a "idroscultura" by the artist Diego Attilio Mario Raco called "Crescendo" is found, inspired by "La città che sale" of Reggio's futurist artist Umberto Boccioni.

\section{First Considerations}

Today, in a context of strong international competition and following a new re-orientation of the demand, the urban asset present in the cities is increasingly becoming a driving force for the economic and local cultural development in a awareness in which it aggregates and integrates resources and services within areas characterized by strong territorial and recognizable identities, in overcoming the fragmentation of the offer. In this context, Reggio Calabria, as well as other European cities, in programming the incentives offered by EU policies towards the development aimed at enhancing the cultural and landscape asset, is ever more spreading the use of new strategies for a local development to integrate the cultural sector and those connected to it, such as tourism, pursued through a territorial specialization and urban policies where the parts of the city become the privileged place for the establishment of cultural facilities or logistics. This arises from the need to put in a network the high concentration of cultural and environmental resources of value with the quality and the concentration of cultural and tourist services, dedicated to users.

However, the first projects, except for the exemplar case of Bologna, of culture of sustainable mobility diffusion, yet they do not create a genuine integration in the local development policies and concern, in general, interventions aimed at reducing pollution or at the regulation of city center access to reduce the burden of traffic. It deals with interventions different from each other and hardly connected in a network point of view, but that have contributed to the awareness of these forms of organization of the territory, attracting considerable interest and attention from the economic, social and territorial institutions towards the prospects of a possible and significant capacity for self-organization of the local contexts.

Today, under the pressure of territory government tools innovative and thanks to a different cultural approach, we are in the condition in which it is possible the recovery and restoration of the territory through the identification of strategies and projects that are able to introduce quality of connective space and cultural kind of services based mainly on promoting the connections and the fruition of this asset. The Regional Addresses (Framework Program Agreement Emergencies Urban and Territorial Intervention Program of the Department of Planning and Government of the Territory of the Calabria Region) ask to abandon the "unsustainable" intervention models and to replace them with " appropriate measures to the safeguard and enhancement of the resources and landscape values still intact along the Calabrian coast, which require an articulated plan of actions for the restructuring and retraining and reorganization of the physiognomy of the coastal system as a whole, capable of understanding the continuity of naturalness, recovery and reorganization of the settlements".

The importance of the theme is also witnessed by numerous initiatives to promote sustainable mobility linked to the urban asset as the recently MUSA project, coordinated by Isfort and developed with Cittalia, Cles and Anci ComuniCare promoted as part of the PON National Governance and System Actions (ESF Ob. Axis Convergence 2007-2013 and Institutional Capacity Ob. Specific 5.1) by the Presidency of the Council of Ministers - Civil Service Department (DPF) - Office of Personnel Training (PA UFPPA). Reggio Calabria is one of eight pilot Administrations part of the project directed to the municipal Administrations on the theme " Sustainable Urban Mobility and Cultural 
Attractors "with the intention of encouraging the development of policies and innovative interventions in key of economical, social and environmental sustainability in urban areas of the ' Convergence Objective. The main objective is to provide the means to strengthen its ability to govern the problems of urban mobility, with a view to greater sustainability and to identify and test innovative models and tools for sustainable territorial planning interventions.

In addition, the MUSA aims to strengthen the capacity building of the public administration in the field of urban mobility and cultural attractions, and start a "subsidiary" building of the reference tools through the involvement of all local actors involved (administrators, institutional representatives, stakeholders). The developments of this project could take a strategic importance for our region in view of the opportunities that are offered to experience a new methodology, able to engage directly with local forces to address the issue of cultural attractors related to sustainable mobility.

The basic idea is to support the construction of a network of urban heritage in mobility systems that are able to undo the imbalances in terms of accessibility / usability, promotion and enhancement. It is now time that city in the idea that all human functions and activities becomes necessary to improve public transport and urban mobility. The center is above the center of culture and tourism in the city, with its fine buildings, monuments, archeology, as well as the rediscovery of the sea thanks to the development of the waterfront. In fact, the element can be able to connect and operate otherwise uneven spaces can be represented exactly by this, or rather from the urban promenade, based on the historical pattern of the promenade, the park - promenade that runs along a linear space, where it is privileged and emphasized the themes of the course and going. The redesign, with a foreshadowing of more or less radical changes made through the construction of new space or connections (routes and itineraries for leisure time, with walking and cycling routes) that become elements of connection between the parts of the city, tends to attribute or return conditions of higher urban quality, in accordance with the principles of environmental sustainability, as well as a strong influence on balanced and spatial dislocation of functions, also on the processes of creation of new places, new public spaces that they can convey meanings of belonging and identity form a collective.

These new spaces must be in line with the new cultural consciousness expressed by the territory and aimed at cultural development through the creation of eco-museums, to nature trails, areas of experimental teaching, etc ..., which could allow the development of strategies for the promotion of the "heritage urban" in view of a general process of development, in a balance between economic competitiveness and environmental compatibility, in which the binding of the inhabitants with their resources plays a key role.

The promenade can be considered a true unified strategy of the territory aimed at ensuring the connection between urban centers, the system of the beaches and public spaces, because the urban promenade thus understood physically as well as visually connects the existing territorial signs and puts in the network cultural historical presences with all the other human activities there.

The proposal for a sustainable mobility project for the use of urban heritage in the territory of Reggio requires evaluations of balances that govern the city and its functions that necessarily involve the introduction of the concept of quality [6]. The efficiency of public transport and utilities, the well-kept historical center, outlying areas integrated with and connected to the entire city, a distinct morphological and cultural identity of the settlement, are, on the whole, the results that a careful plan to sustainability issues should be able to achieve.

It could therefore be from the exploitation of parts "emerging" in the city to get a re-assignment identity of the areas that do not have recognizable features. The culture of the place and the quality of urban life should be understood as a reference to "key" to every human activity, to be taken as guidelines that can combine all the evolutions of the "big choices" for the area. 


\section{References}

[1] Information on http://www.euromobility.org/Osservatorio50citta/

[2] Interministerial Decree Sustainable Mobility in Urban Areas, Ronchi Decree, 1998

[3] Official web site of Reggio Calabria Municipality. Information on http://www.comune.reggio-calabria.it/

[4] Urban Mobility Plan (PUM) of the Municipality of Reggio Calabria

[5] A.M. Cassalia, F. Melchini, S. Putortì, A. Taglieri: Il piano comunale di spiaggia. Strumento di riqualificazione del Waterfront, in C. Fallanca a cura di, Genius Loci. Governance e Territorio, Iiriti Editore, Reggio Calabria (ITA) (2008)

[6] C. Fallanca (a cura di): La valorizzazione del patrimonio urbano attraverso modelli innovativi di mobilità sostenibile, Iiriti Editore, Reggio Calabria (ITA) (2013) 